\title{
Digestibilidade de alimentos protéicos e energéticos para fêmeas de beta
}

\section{Jener Alexandre Sampaio Zuanon ${ }^{1}$, Hamilton Hisano ${ }^{2}$, Dario Rocha Falcon ${ }^{3}$, Fernanda Garcia Sampaio ${ }^{4}$, Margarida Maria Barros ${ }^{5}$, Luiz Edivaldo Pezzato ${ }^{5}$}

\author{
${ }^{1}$ Departamento de Biologia Animal - UFV, Av. P. H. Rolfs s/n, CEP: 36570-000, Viçosa MG. \\ 2 Embrapa - Agropecuária Oeste, BR 163, km 253,6, Caixa Postal 661, CEP: 79804-970, Dourados, MS. \\ 3 Programa de Pós-Graduação em Zootecnia da FMVZ/UNESP, Campus de Botucatu, C.P. 560, CEP: 18618-000, Botucatu, SP. \\ ${ }^{4}$ Programa de Pós-Graduação em Ciências Fisiológicas - Departamento de Ciências Fisiológicas da Universidade Federal de São Carlos, \\ Via Washington Luiz, km 235, CEP: 13565-905 - São Carlos, SP. \\ ${ }^{5}$ Departamento de Nutrição Animal, FMVZ/UNESP, Campus de Botucatu, C.P. 560, CEP: 18618-000, Botucatu, SP.
}

RESUMO - Foram avaliados os coeficientes de digestibilidade aparente de MS, PB, energia bruta (EB) e EE de alimentos protéicos (farelo de soja e farinha de peixe) e energéticos (fubá de milho e farelo de trigo) para beta (Betta splendens). Fêmeas adultas foram alojadas em gaiolas e mantidas em dois aquários de fibra de vidro (30 peixes/aquário) para alimentação e dois para coleta de fezes, ambos de formato cônico e com capacidade para 30 L. Os resultados dos coeficientes de digestibilidade aparente de MS, PB, EB e EE foram, respectivamente, de 69,43; 72,52; 67,91 e 55,50\% para farelo de soja; 60,67; 51,15; 75,55 e 58,26\% para farinha de peixe; 63,88; 87,16; 77,61 e 50,40\% para fubá de milho; e 61,06; 93,37; 58,17 e 65,51\% para farelo de trigo. Os resultados obtidos neste estudo permitem otimizar a formulação de dietas práticas balanceadas, economicamente viáveis para a espécie.

Palavras-chave: Betta splendens, nutrição, peixe de briga, peixes ornamentais

\section{Digestibility of protein feedstuffs and energetic feedstuffs for female beta}

\begin{abstract}
Apparent digestibility coefficients of dry matter, crude protein, gross energy and ether extract from protein feeds: soybean meal and fish meal and from energy feeds: corn and wheat middlings were evaluated for Siamese fighting fish (Betta splendens). Adult female fish were stocked in cages and held in two fiberglass aquaria (30 fish/aquarium) for feeding and two aquaria for collect fecal samples, both with conic shape with 30L. The results of apparent digestibility coefficients for DM, CP, GE and EE were respectively 69.43, 72.52, 67.91 and 55.50\% for soybean meal; 60.67, 51.15, 75.55 and 58.26\% for fish meal; 63.88, 87.16, 77.61 and $50.40 \%$ for corn and 61.06, 93.37, 58.17 and $65.51 \%$ for wheat middlings. The determined digestibility values are essential to economically viable practical diet formulation for Siamese fish fighting.
\end{abstract}

Key Words: Betta splendens, nutrition, ornamental fish, Siamese fighting fish

\section{Introdução}

A produção de peixes ornamentais é uma modalidade da aqüicultura em plena expansão nas últimas décadas. Nos Estados Unidos, a popularidade e os altos valores de venda têm situado a produção de peixes ornamentais entre as principais fontes de renda da aqüicultura (Chapman et al., 1997). No comércio internacional de organismos aquáticos ornamentais, observa-se aumento anual a uma taxa média de 14\%, chegando a cifras superiores a 200 milhões de dólares por ano para as exportações (Lima et al., 2001).

Na América do Sul, pouca atenção tem sido dada à criação de peixes ornamentais, provavelmente pelo fato de a exportação ser baseada na coleta de peixes na natureza (Conroy, 1975). No Brasil, a produção de peixes ornamentais é bastante recente e surgiu com a implantação de projetos de piscicultura na década de 70. O estado de Minas Gerais destaca-se como o maior centro de produção do Brasil, com 118 criadores que cultivam 50 variedades e/ou espécies (Pezzato \& Scorvo Filho, 2000). Entretanto, o Brasil participa com apenas 6,5\% das importações no mercado norteamericano (OFI Journal, 1999), indicando a necessidade de maior apoio e incentivo à atividade, tendo em vista o grande potencial nacional.

Atualmente, existem poucos estudos sobre as exigências nutricionais da maioria das espécies ornamentais e, conseqüentemente, não existem dietas comerciais balanceadas específicas para utilização na produção em larga escala. Para formulação de dietas práticas, é necessário o conhecimento não só das características químicas e físicas de cada ingrediente, mas também de sua digestibilidade pelos peixes (Tacon \& Rodrigues, 1984). Os nutrientes não digeridos 
dos alimentos, além das implicações no crescimento e dos custos de alimentação, aumentam os níveis de nitrogênio, fósforo e matéria orgânica nos efluentes (Chong et al., 2002). Portanto, o conhecimento da eficiência de utilização dos nutrientes de alguns alimentos é primordial para formulação de dietas para diversas espécies de peixes.

Os valores de digestibilidade de nutrientes de alimentos para peixes ornamentais ainda não estão estabelecidos (Sales \& Janssens, 2003) e revelam que essa lacuna de informações está diretamente relacionada à dificuldade de coleta do material para análise de digestibilidade, à diversidade de espécies com diferentes hábitos alimentares, à carência de investigações básicas, aos fatores econômicos e até mesmo ao relativo desinteresse de pesquisadores, universidades e centros de pesquisa.

Entre algumas espécies ornamentais, o beta (peixe de briga ou Siamese fighting fish) destaca-se como um dos peixes de melhor mercado, não só pela beleza e variedade de cores, como também pela rusticidade, associada à presença de um sistema acessório de respiração aérea que lhe permite sobreviver em pequenos aquários (beteiras). Esta espécie ornamental é uma das cinco mais importadas pelos Estados Unidos, tanto em número de peixes como em dólares gastos anualmente (Chapman et al., 1997).
Neste estudo, objetivou-se avaliar o coeficiente de digestibilidade aparente de alguns alimentos comumente utilizados em dietas para peixes visando à otimização da formulação de dietas para Betta splendens.

\section{Material e Métodos}

O experimento foi realizado no Laboratório de Nutrição de Organismos Aquáticos (Aquanutri) do Departamento de Melhoramento e Nutrição Animal, Faculdade de Medicina Veterinária e Zootecnia, Unesp, Botucatu, unidade integrada ao Centro de Aqüicultura da Unesp.

Foram avaliados os coeficientes de digestibilidade aparente de MS, PB, EE e EB da dieta basal e de alimentos energéticos e protéicos (fubá de milho, farelo de trigo, farelo de soja e farinha de peixe), incluídos no nível de $40 \%$ da dieta basal purificada (Tabela 1). A composição percentual das dietas basal e teste encontram-se na Tabela 1 e a composição química analisada da dieta basal na Tabela 2. Fêmeas adultas de Betta splendens (0,35 $\pm 0,08 \mathrm{~g})$ foram mantidas em dois aquários de fibra de vidro (30 peixes/aquário) para alimentação e dois aquários para coleta de fezes, ambos de formato cônico e com capacidade para 30 L. Para minimizar o estresse e facilitar o manejo de alimentação e coleta de fezes, os peixes foram alojados em tanques-rede de formato

Tabela 1 - Composição percentual das dietas experimentais (matéria natural)

Table 1 - Percentage composition of the experimental diets (as-fed basis)

\begin{tabular}{|c|c|c|c|c|c|}
\hline \multirow[t]{2}{*}{$\begin{array}{l}\text { Ingrediente } \\
\text { Ingredient }\end{array}$} & \multicolumn{5}{|c|}{$\begin{array}{l}\text { Dieta } \\
\text { Diet }\end{array}$} \\
\hline & $\begin{array}{l}\text { Dieta basal } \\
\text { Basal diet }\end{array}$ & $\begin{array}{c}\text { Fubá de milho (40\%) } \\
\text { Corn meal }\end{array}$ & $\begin{array}{c}\text { Farelo de trigo ( } 40 \%) \\
\text { Wheat middlings }\end{array}$ & $\begin{array}{c}\text { Farelo soja }(40 \%) \\
\text { Soybean meal }\end{array}$ & $\begin{array}{c}\text { Farinha peixe }(40 \%) \\
\text { Fish meal }\end{array}$ \\
\hline Albumina (Albumine) & 32,00 & 19,20 & 19,20 & 19,20 & 19,20 \\
\hline Gelatina (Gelatine) & 7,70 & 4,62 & 4,62 & 4,62 & 4,62 \\
\hline Amido de milho (Corn starch) & 44,13 & 26,48 & 26,48 & 26,48 & 26,48 \\
\hline Fosfato bicálcico (Dicalcium phosphate) & 3,00 & 1,80 & 1,80 & 1,80 & 1,80 \\
\hline Suplemento vitamínico e mineral ${ }^{2}$ & 0,50 & 0,30 & 0,30 & 0,30 & 0,30 \\
\hline \multicolumn{6}{|l|}{ Vitamin and mineral premix } \\
\hline Vitamina $C^{3}$ (Vitamin C) & 0,05 & 0,03 & 0,03 & 0,03 & 0,03 \\
\hline $\mathrm{NaCl}$ & 0,50 & 0,30 & 0,30 & 0,30 & 0,30 \\
\hline $\mathrm{BHT}^{4}$ & 0,02 & 0,01 & 0,01 & 0,01 & 0,01 \\
\hline Farinha de peixe (Fish meal) & - & - & - & - & 39,96 \\
\hline
\end{tabular}

${ }^{1} \alpha$-celulose $(\alpha$-cellulose): EB $(G E)=3.658,86 \mathrm{kcal} / \mathrm{kg} ; \mathrm{PB}(\mathrm{CP})=1,80 \% ; \mathrm{FB}(\mathrm{CF})=75 \% ; \mathrm{Ca}=0,28 \%$ e $\mathrm{P}=0,08 \%$.

2 Premix vitamínico e mineral (vitamin and mineral premix) (Supre Mais): nível de garantia por kg do produto (quarantee level per $\mathrm{kg}$ of product): vit. A = 1.200.000 UI; vit. D3 = $200.000 \mathrm{UI}$; vit. $\mathrm{E}=12.000 \mathrm{mg}$; vit. $\mathrm{K} 3=2.400 \mathrm{mg}$; vit. $\mathrm{B} 1=4.800 \mathrm{mg}$; vit. $\mathrm{B} 2=4.800 \mathrm{mg}$; vit. $\mathrm{B} 6=4.000 \mathrm{mg}$; biotina (biotin) $=48 \mathrm{mg}$; colina (choline) $=65.000 \mathrm{mg} ;$ niacina $($ niacin $)=24.000 \mathrm{mg} ; \mathrm{Fe}=10.000 \mathrm{mg} ; \mathrm{Cu}=600 \mathrm{mg} ; \mathrm{Mn}=4.000 \mathrm{mg} ; \mathrm{Zn}=6.000 \mathrm{mg} ; \mathrm{I}=20 \mathrm{mg} ; \mathrm{Co}=2 \mathrm{mg}$ e Se $=20 \mathrm{mg} ;$

3 vitamina C (vitamin C): sal cálcica 2-monofosfato de ácido ascórbico - 42\% de princípio ativo (calcium salt 2- monophosphate of ascorbic acid - $42 \%$ of activity);

${ }^{4}$ BHT: Butil hidróxido tolueno (Butil hidroxi toluene). 
circular, confeccionados com tela plástica (malha de $3 \mathrm{~mm}$ entre nós).

No intervalo de 24 horas, foram realizadas duas coletas de fezes, intercaladas por períodos de alimentação. Os peixes foram mantidos de 8 às $11 \mathrm{~h}$ nos aquários de alimentação, onde receberam as dietas experimentais ad libitum a cada 30 minutos. Ao final desse período, foram transferidos para os aquários de coleta de fezes, onde permaneceram até as 14 h. Após a coleta de fezes, os peixes foram devolvidos aos aquários de alimentação, onde foram novamente arraçoados a cada 30 minutos, até às $18 \mathrm{~h}$. Ao final do segundo período de alimentação, os peixes foram transferidos para os aquários de coleta, onde permaneceram até às $8 \mathrm{~h}$ do dia seguinte. Ao final de cada período de alimentação, foi realizada a limpeza dos aquários, preparando-os para nova coleta. Portanto, foram realizadas duas coletas de fezes por dia.

O mesmo grupo de peixes foi utilizado para a coleta de fezes de todas as dietas, porém, adotou-se um período de sete dias de aclimatação às dietas antes de iniciar a coleta de fezes da dieta seguinte.

Em virtude da pequena quantidade de fezes obtida para cada dieta, as análises laboratoriais foram realizadas em um pool das fezes dos dois períodos de coleta. As amostras de fezes foram centrifugadas, secas em estufa de ventilação forçada a $55 \pm 5^{\circ} \mathrm{C}$ durante 24 horas e moídas. A determinação da composição químico-bromatológica das dietas e das fezes foi realizada segundo metodologia descrita pela AOAC (1995) e a concentração do óxido de cromo, segundo Bremer Neto et al. (2003), analisadas em duplicata. O coeficiente de digestibilidade aparente (CDA) dos nutrientes da dieta basal e das dietas experimentais foi calculado pelo método indireto utilizando-se óxido de cromo como marcador inerte, por meio das expressões propostas por Cho et al. (1985):

$$
C D a_{(n)}=100-\left[100 *\left(\frac{\% C r_{2} O_{3 r}}{\% C r_{2} O_{3 f}}\right) *\left(\frac{\% N_{f}}{\% N_{r}}\right)\right]
$$

em que $\mathrm{CDa}_{(\mathrm{n})}=$ coeficiente de digestibilidade aparente do nutriente na ração basal e rações experimentais; $\% \mathrm{Cr}_{2} \mathrm{O}_{3 \mathrm{r}}=$ porcentagem de óxido crômio na ração; $\% \mathrm{Cr}_{2} \mathrm{O}_{3 \mathrm{f}}=$ porcentagem de óxido crômio nas fezes; $\% \mathrm{~N}_{\mathrm{r}}=$ porcentagem do nutriente na ração; $\% \mathrm{~N}_{\mathrm{f}}=$ porcentagem do nutriente nas fezes.

Os coeficientes de digestibilidade aparente dos nutrientes nos diferentes alimentos foram calculados pela seguinte expressão:

$$
C D a_{(i n g)}=\frac{C D a_{(r t)}-b \cdot C D a_{(r b)}}{a}
$$

em que $\mathrm{CDa}_{\text {(ing) }}=$ coeficiente de digestibilidade aparente do nutriente no ingrediente; $\mathrm{CDa}_{(\mathrm{rt})}=$ coeficiente de digestibilidade aparente do nutriente na dieta com o ingrediente teste; $\mathrm{CDa}_{(\mathrm{rb})}=$ coeficiente de digestibilidade aparente do nutriente na dieta basal; $b$ = porcentagem da dieta basal na dieta-teste; $\mathrm{a}$ = porcentagem do ingrediente na dieta-teste.

O oxigênio dissolvido (mg/L) e o $\mathrm{pH}$ foram aferidos semanalmente por meio de oxímetro e peagâmetro digitais, respectivamente, e a temperatura da água dos aquários, diariamente, às 8 e $16 \mathrm{~h}$.

\section{Resultados e Discussão}

Durante o período experimental, a temperatura da água foi de $26,0 \pm 0,5^{\circ} \mathrm{C}$. O nível médio de oxigênio dissolvido foi de 7,85 \pm 0,33 mg/L, valor considerado satisfatório para o desenvolvimento dos peixes (Boyd, 1990). O valor médio de pH foi de 6,92 \pm 0,32, considerado satisfatório para a espécie, segundo Rainboth (1996).

Os coeficientes de digestibilidade aparente dos nutrientes (MS, PB, EE e EB) e os valores de proteína digestível e energia digestível do farelo de soja, da farinha de peixe, do fubá de milho e do farelo de trigo obtidos para o Betta splendens são descritos na Tabela 2.

Entre os alimentos avaliados, o farelo de soja apresentou o maior coeficiente de digestibilidade da MS (69,43\%). Os coeficientes de digestibilidade da MS do farelo de soja ( $71,04 \%)$ e da farinha de peixe $(57,46 \%)$ foram semelhantes aos obtidos por Pezzato et al. (2002) para tilápia-do-nilo, enquanto os do milho foram superiores $(52,52 \%)$ e os do farelo de trigo (66,05\%) inferiores. Chong et al. (2002), avaliando a digestibilidade in vivo de alguns alimentos para uma das espécies mais populares de peixes ornamentais, o acará-disco (Symphysodon aequifasciata), obtiveram bons coeficientes de digestibilidade da MS para a maioria dos alimentos avaliados, como a farinha de peixe $(78,15 \%)$ e o farelo de soja (66,22\%). Entretanto, o valor encontrado para o farelo de trigo $(49,03 \%)$ foi inferior ao observado para o beta. Cho \& Bureau (1997) obtiveram baixos coeficientes de digestibili-dade da MS para o milho (23\%) е o farelo de trigo (35\%) e maiores valores para o farelo de soja (74\%) e a farinha de peixe (85\%) em estudo com truta arco-íris (Oncorhynchus mykiss).

Os coeficientes de digestibilidade da PB dos alimentos energéticos (fubá de milho e farelo de trigo) foram maiores que os dos alimentos protéicos (farelo de soja e farinha de peixe). Pezzato et al. (2002), avaliando os coeficientes de digestibilidade da PB em tilápias-do-nilo, obtiveram valores superiores para os coeficientes de digestibilidade da PB 
Tabela 2 - Coeficiente de digestibilidade aparente de MS, PB, EB e EE dos alimentos e valores de proteína e energia digestível para Betta splendens

Table 2 - Apparent digestibility coefficients of DM, CP, GE and EE of feedstuffs and digestible protein (DP) and digestible energy (DE) for Betta splendens

\begin{tabular}{|c|c|c|c|c|c|c|}
\hline \multirow[t]{3}{*}{$\begin{array}{l}\text { Ingrediente } \\
\text { Ingredient }\end{array}$} & \multicolumn{6}{|c|}{$\begin{array}{c}\text { Coeficiente de digestibilidade aparente (\%) } \\
\text { Apparent digestibility coefficient }\end{array}$} \\
\hline & MS & $\mathrm{PB}$ & EB & EE & $\mathrm{PD}^{1}(\%)$ & $\mathrm{ED}^{1}(\mathrm{kcal} / \mathrm{kg})$ \\
\hline & $D M$ & $C P$ & $G E$ & $E E$ & $D P(\%)$ & $D E(\mathrm{kcal} / \mathrm{kg})$ \\
\hline \multicolumn{7}{|l|}{ Alimento protéico (Protein feeds) } \\
\hline Farelo de soja (Soybean meal) & 69,43 & 72,52 & 67,91 & 55,50 & 33,03 & $2.780,24$ \\
\hline Farinha de peixe (Fish meal) & 60,67 & 51,15 & 75,55 & 58,26 & 27,89 & $3.304,56$ \\
\hline \multicolumn{7}{|l|}{ Alimento energético (Energy feeds) } \\
\hline Fubá de milho (Corn) & 63,88 & 87,16 & 77,61 & 50,40 & 7,47 & $3.052,40$ \\
\hline Farelo de trigo (Wheat middlings) & 61,06 & 93,37 & 58,17 & 65,51 & 15,44 & $2.295,39$ \\
\hline
\end{tabular}

${ }^{1}$ Cálculos efetuados com base nos valores tabelados (Rostagno, 2000) de proteína bruta e energia bruta de cada alimento.

${ }^{1}$ Crude protein and gross energy of feedstuffs were calculated based on values showed by (Rostagno, 2000).

dos alimentos energéticos (87,69\%) e protéicos de origem vegetal (87,85\%) em comparação aos alimentos protéicos de origem animal $(63,76 \%)$. Entretanto, os coeficientes de digestibilidade da PB do milho (95\%), do farelo de trigo (92\%), do farelo de soja (96\%) e da farinha de peixe (92\%) encontrados por Cho \& Bureau (1997) para a truta arco-íris foram altos e semelhantes entre si.

Os baixos valores de digestibilidade aparente da proteína da farinha de peixe podem ter sido negativamente influenciados pelo processamento ou pela composição química do alimento (Sullivan \& Reigh, 1995). Segundo Aksnes et al. (1997), as farinhas de peixe disponíveis no mercado apresentam grande variação na qualidade, o que pode ser atribuído ao frescor, ao tipo de material e às condições de processamento. Em 27 amostras de farinha de peixe, Romero et al. (1994) observaram variação de 84,5 a 97,0\% para digestibilidade da proteína na truta arco-íris. As farinhas de peixe brasileiras apresentam muitas vezes baixos coeficientes de digestibilidade por serem formuladas com resíduos de abate, podendo apresentar altas porcentagens de cinzas e proteína de baixa qualidade, proveniente da matriz protéica dos ossos, da pele, das escamas e das vísceras (Boscolo et al., 2004).

Os melhores coeficientes de digestibilidade da energia bruta foram obtidos para o fubá de milho $(77,61 \%)$ e para a farinha de peixe (75,55\%) em comparação ao farelo de soja $(67,91 \%)$ e ao farelo de trigo (58,17\%). Essas diferenças na digestibilidade da fração energética desses alimentos podem ser conseqüência dos altos teores de fibra bruta no farelo de soja (5,41\%) e no farelo de trigo (9,66\%). Anderson et al. (1983) e Lanna et al. (2004), em experimento com tilápiasdo-nilo, e Esquivel et al. (1998), com piracanjuba Brycon orbgnyanus, concluíram que altos níveis de fibra bruta na dieta diminuem o tempo de passagem do alimento no intes- tino, piorando o aproveitamento dos nutrientes. De forma semelhante, Kirchgessner et al. (1986) observaram piores coeficientes de digestibilidade dos carboidratos totais na carpa-comum Cyprinus carpio alimentada com altos níveis de fibra bruta na dieta.

Em geral, os coeficientes de digestibilidade do EE foram baixos e melhores para o farelo de trigo, seguido da farinha de peixe, do farelo de soja e do fubá de milho. Apenas o farelo de trigo apresentou coeficientes de digestibilidade da fração lipídica similares aos observados por Pezzato et al. (2002) em tilápias-do-nilo (67,37\%), enquanto os valores encontrados para o milho (69,02\%), o farelo de soja $(82,67 \%)$ e a farinha de peixe $(80,12 \%)$ foram inferiores.

Apesar de o beta se alimentar em seu ambiente natural de zooplâncton, zoobentos e larvas de insetos (Rainboth, 1996), os coeficientes de digestibilidade dos alimentos de origem vegetal foram satisfatórios e comprovaram bom aproveitamento dos nutrientes e da energia desses alimentos. Esses resultados indicam a possibilidade de substituição da farinha de peixe por fontes protéicas vegetais, o que contribui para diminuição dos custos de produção dessa espécie. Além disso, informações sobre a digestibildade dos principais nutrientes desses alimentos permitem a formulação de dietas mais adequadas à espécie, de forma a minimizar os excessos e desperdícios de nutrientes, reduzindo assim a eutrofização da água de cultivo e o impacto ao meio ambiente.

\section{Conclusões}

Informações sobre a energia digestível e a digestibilidade de MS, PB e EE de alimentos de origem vegetal permitirão a formulação de dietas mais adequadas à espécie e a minimização dos excessos e desperdícios de nutrientes, podendo reduzir a eutrofização da água de cultivo e o impacto ao meio ambiente. 


\section{Agradecimento}

Ao piscicultor Eloy Manuel Clemente de Rosário, de Limeira - MG, pela cessão dos peixes para o experimento.

\section{Literatura Citada}

AKSNES, A.; IZQUIERDO, M.S.; ROBAINA, L. et al. Influence of fish meal quality and feed pellet on growth, feed efficiency and muscle composition in gilthead seabream (Sparus aurata). Aquaculture, v.153, p.251-261, 1997.

ANDERSON, J.; JACKSON, A.J.; MATTY, A.J. Effects of carbohydrates and fiber on the growth of the Oreochromis niloticus. In: INTERNATIONAL SYMPOSIUM ON TILAPIA, 1983, Nazareth, Israel. Anais... Nazareth, Israel: ISA, 1983. p.80.

ASSOCIATION OF OFFICIAL ANALYTICAL CHEMISTS - AOAC. Official methods of analysis. 16.ed. Washington, D.C.: 1995. 1094p.

BOSCOLO, W.R.; HAYASHI, C.; MEURER, F. et al. Digestibilidade aparente da energia e proteína das farinhas de resíduos da filetagem da tilápia do Nilo (Oreochromis niloticus) e da corvina (Plagioscion squamosissimus) e farinha integral do camarão canela (Macrobrachium amazonicum) para a tilápia do Nilo. Revista Brasileira de Zootecnia, v.33, n.1, p.8-13, 2004.

BOYD, C.E. Water quality management in ponds for fish culture. Development in Aquaculture and Fisheries Science. New York: Elsevier Scientific Publishing Company, 1990. 482p.

BREMER NETO, H.; PEZZATO, L.E.; GRANER, C.A.F. Determinação do teor de óxido de crômio (III) usado como marcador externo. Revista Brasileira de Zootecnia, v.32, n.2, p.249-255, 2003.

CHAPMAN, F.A.; FITZ-COY, S.A.; THUNBERG, E.M. et al. United States of America trade in ornamental fish. Journal of the World Aquaculture Society, v.28, n.1, p.1-10, 1997.

CHO, C.Y.; BUREAU, D.P. Reduction of waste output from salmonid aquaculture through feeds and feeding. The Progressive Fish Culturist, v.59, p.155-160, 1997.

CHO, C.Y.; COWEY, C.B.; WATANABE, T. Finfish nutrition in Asia: methodological approaches to research and development. Otawa: IDRC, 1985. 145p.

CHONG, A.S.C.; HASHIM, R.; ALI, A.B. Assessment of dry matter and protein digestibilities of selected raw ingredients by discus fish (Symphysodon aequifasciata) using in vivo and in vitro methods. Aquaculture Nutrition, v.8, p.229-238, 2002.

CONROY, D.A. An evaluation of the present state of world trade in ornamental fish. FAO Fisheries Technical Paper, n.146, 1975. 128p.
ESQUIVEL, J.G.; PEZZATO, L.E.; ZANIBONI FILHO, E. et al. Ação da fibra bruta sobre a digestibilidade aparente da proteína e trânsito gastrintestinal da piracanjuba (Brycon orbgnyanus). Boletim Técnico do CEPTA, v.11, p.59-69, 1998.

KIRCHGESSNER, M.; KÜRZINGER, H.; SCHWARTZ, F.J. Digestibility of crude nutrients in different feeds and estimation of their energy content for carp (Cyprinus carpio). Aquaculture, v.58, p.185-194, 1986.

LANNA, E.A.T.; PEZZATO, L.E.; CECON, P.R. et al. Digestibilidade aparente e trânsito gastrintestinal em tilápia do Nilo (Oreochromis nilotius), em função da fibra bruta da dieta. Revista Brasileira de Zootecnia, v.33, n.6, p.2186-2192, 2004.

LIMA, A.O.; BERNARDINO, G.; PROENÇA, C.E.M. Agronegócio de peixes ornamentais no Brasil e no mundo. Panorama da Aqüicultura, v.11, n.65, p.14-24, 2001.

ORNAMENTAL FISH INTERNATIONAL JOURNAL - OFI Journal. [1999]. European importer's survey results. Disponível em:<http://www.ornamental_fish_int.org/data.htm> Acesso em: 20/05/00

PEZZATO, L.E.; MIRANDA, E.C.; BARROS, M.M. et al. Digestibilidade aparente de ingredientes pela Tilápia do Nilo (Oreochromis niloticus). Revista Brasileira de Zootecnia, v.31, n.4, p.1595-1604, 2002.

PEZZATO, L.E.; SCORVO FILHO, J.D. Situação atual da aqüicultura na Região Sudeste. In: VALENTI W.C. (Ed.) Aqüicultura no Brasil: bases para um desenvolvimento sustentável. Brasília: CNPq/Ministério da Ciência e Tecnologia, 2000. p.303-322.

RAINBOTH, W.J. Fishes of the cambodian mekong. FAO species identification field guide for fishery purposes. Rome: FAO, 1996. 265p.

ROMERO, J.J.; CASTRO, E.; DÍAZ, A.M. et al. Evaluation of methods to certify the "premium" quality of Chilean Fish Meals. Aquaculture, v.124, n.1-4, p.351-358, 1994.

ROSTAGnO, H.S. Tabelas brasileiras para aves e suínos: composição de alimentos e exigências nutricionais. Viçosa, MG: Universidade Federal de Viçosa, 2000. 141p.

SALES, J.; JANSSENS, G.P.J. Nutrient requeriments of ornamental fish. Aquatic Living Resource, v.16, p.533-540, 2003.

SULLIVAN, J.A.; REIGH, R.C. Apparent digestibility of selectedd feedstuffs in diets for hybrid striped bass (Morone saxatilis $\mathrm{x}$ Moreone chysops). Aquaculture, v.138, p.313-322, 1995.

TACON, A.G.J.; RODRIGUES, A.M.P. Comparison of chromic oxide, crude fiber, polyethylene and acid insoluble ash as dietary markers for the estimation of apparent digestibility coefficients in rainbow trout. Aquaculture, v.43, p.391-399, 1984. 